\title{
EMIC-GRACIÓN: FRONTERAS DE PIEL, SEXO Y PAPEL
}

\author{
EMIC-GRATION: FRONTIERS OF SKIN, SEX, AND PAPER \\ Guadalupe Gómez Abeledo* y Eleder Piñeiro Aguiar**
}

\begin{abstract}
En este texto de carácter teórico-reflexivo analizamos e interpretamos las experiencias de migrantes llegados a Europa en el marco de un proyecto de investigación en torno a los Fondos Europeos para la Integración, donde realizamos trabajo de campo por un periodo de 3 años. Proponemos el concepto de "emic-gración" como propuesta analítica en torno al cuádruple eje de racismointerculturalidad-resiliencia-autobiografías, para ello en primer lugar exponemos las metodologías activistas con colaboradores migrantes que llegan a destino; a continuación presentamos ciertas limitaciones metodológicas a la investigación (estadocentrismo, racismo, subalternidad); en tercer lugar exponemos y discutimos los relatos migrantes en el campo y a nivel teórico; en el último apartado se exponen unas conclusiones a modo de propuestas y alternativas interculturales de investigación que rompan con los dualismos clásicos objeto-sujeto.
\end{abstract}

Palabras clave: Fronteras, interculturalidad, emic-gración, trato, sexo, piel y papel.

In this theoretical-reflexive text, we analyze and interpret the experiences of immigrants arriving in Europe within the framework of a research project on European Integration Funds, where we carry out field work for a period of 3 years. We propose the concept of "emic-gration" as an analytical proposal around the fourfold axis of racism-interculturality-resilience-autobiographies, for which we first expose the activist methodologies with the migrant collaborators who arrive at their destination; Below we present certain methodological limitations for research (state statism, racism, subalternity); third, we expose and discuss the histories of migrants in the field and at the theoretical level; In the last section, the conclusions are presented as proposals for intercultural research and alternatives that break with classical object-subject dualisms.

Key words: Borders, interculturality, emic-gration, treatment, sex, skin and paper.

\section{Introducción}

" Otra cara Africana primitiva que viene a contaminar el aire alemán oh-tan-puro y a trufarlo probablemente con más bebés tostados que nadie quiere!" (Darko, 1991: 87). Así puede imaginar Amma Darko, en su libro Horizontes lejanos, el recibimiento que tiene una mujer de Ghana en Alemania, lo que podría ser uno de tantos estudios de caso acerca de la movilidad humana global en la actualidad. Con el fin de hacer un "frente común" a las consecuencias de dicha movilidad, surgen los Fondos Europeos para la Integración de Nacionales de Terceros Países (en adelante fondos FEI), los que estuvieron vigentes entre 2007 y 2013 y dotados con 625 millones de euros. Su objetivo general fue "apoyar los esfuerzos de los Estados miembros para hacer posible que nacionales de terceros países con diversos orígenes económicos, sociales, culturales, religiosos, lingüísticos y étnicos reúnan las condiciones de residencia y facilitar la integración de estos en las sociedades europeas".

Nuestro trabajo en el campo -Alicante, Madrid y Palma de Mallorca, en España- a cargo de los fondos FEI, a lo largo de tres años, nos facilitó un acercamiento al contexto que más tarde devino en una investigación activista (Speed, 2006) y de la que algunas de las aproximaciones y perspectivas compartidas discutiremos en este artículo. Qué hemos aprendido y qué debemos compartir son las principales inquietudes epistemológicas en este sentido.

Partimos, a nivel teórico, desde el concepto de interseccionalidad (Crenshaw, 1991), el que pretende suscitar en las y los responsables políticos y activistas una reflexión acerca de las dinámicas de privilegios y exclusiones que emergen cuando no se presta suficiente atención a las personas que se encuentran en el punto de intersección entre distintas desigualdades (G. Y. F. V. 2010: 12). El enfoque desde

\footnotetext{
* Universidad Técnica “Luis Vargas Torres” de Esmeraldas, Ecuador. Universidad Nacional de Educación a Distancia, España. Grupo INTER. Correo electrónico: guadadeza@hotmail.com

** Universidad Adolfo Ibáñez, Facultad de Artes Liberales. Viña del Mar, Chile. Correo electrónico: elederpa1983@gmail.com
} 
la interseccionalidad nos da un espectro teóricopráctico más amplio para analizar el impacto que tienen las marginalidades acumulativas en la llegada de la migrada, lo que ha venido siendo materia de análisis por parte de numerosos científicos sociales (Collins, 2000; Platero, 2012). De lo que se trata en el fondo es de criticar los sistemas de opresión, explotación e invisibilización en el que se ven envueltos sujetos y grupos debido a sus categorías identitarias en torno a raza, origen, clase, religión, sexualidad, etc., analizando "cómo diferentes fuentes estructurales de desigualdad mantienen relaciones recíprocas" (Platero, 2012: 26), que, además, se potencian unas a otras, empeorando las situaciones de relación en las que se ve envuelto el/la sujeto.

Asimismo, acuñamos el término "emic-gración" por cuanto tratamos el hecho migratorio contado desde la experiencia personal y en el lugar de llegada, lo que supone la aceptación de un diálogo tanto endógeno como exógeno sin caer en los riesgos que dicho diálogo puede entrañar (Appadurai, 2008) y sin tener en consideración la posesión o no de cédula/ visa/papeles de residencia, los que entendemos que funcionan en no pocas ocasiones a modo de fetiche (Suárez Navas et al., 2007). Ambos investigadores nos situamos en el campo como herederos de una cultura migrante y como migrantes también, lo que nos coloca en el centro del concepto emic-gración pero sin eximirnos como investigadores de sesgos de los que somos conscientes.

Desde el campo de la antropología, el debate emic-etic ha estado presente desde la introducción por parte del lingüista Kenneth Pike (1967), y profundamente criticados desde entonces por cuanto desde el giro lingüístico y posmoderno revisaron las dualidades de dichos términos, apostando por toda una crítica a la autoridad etnográfica y a las relaciones objeto-sujeto, así como a las categorías de informante, investigador, nativo, etc. (Clifford, 1998; Díaz de Rada, 2012). No tratamos en estas líneas de contraponer enfoques teóricos al respecto, al contrario, proponemos la posibilidad del relato autobiográfico como profundizador en esa forma no aséptica y neutral de obtener datos, informaciones y conocimientos. La técnica biográfica (Pujadas, 2000) se ha venido realizando desde la metodología de las ciencias sociales al menos desde los años 20 del siglo pasado con las investigaciones de la Escuela de Chicago en torno a la llegada de migrantes a dicha ciudad, si bien en este texto lo que se demanda es una mayor asimetría, e incluso ruptura, entre sujeto y objeto. Las historias de vida deben ser citadas aquí por cuanto las subjetividades son precisamente voces autorizadas por y del migrante, lo que a su vez nos permite autodotarnos de autoridad científica transformándonos en potenciadores de dichas voces, y es que cuando se relata una experiencia personal los matices se vuelven exponenciales. Por su determinación originaria, la hermenéutica es el arte de explicar y transmitir por el esfuerzo propio de la interpretación lo que, dicho por otro, nos sale al encuentro en la tradición, la que es siempre inventada (Hobsbawn y Ranger, 1983.orig.), siempre que no sea comprensible de un modo inmediato (Gadamer, Pujol y Ramos, 2006: 3).

Partimos del supuesto de que una etnografía sin autobiografías de la inmigración es solamente hacer "medio campo". Dicho campo nos da el sustento en la etnografía pero el cómo adquirimos ese sustento tiene mucho que ver con la ideología social. En otro nivel, las ideologías también establecen vínculos entre el discurso y la sociedad. En ese sentido, las ideologías son la contraparte cognitiva del poder (Van Dijk, 2000: 27). Investigamos con instrumentos que nacen de un contexto, no libre de ideología social, lo que repercute entre otras cosas en la forma de encarar las preguntas de investigación.

En el trabajo de campo desarrollado a lo largo de tres años la metodología fue la cualitativa basada en técnicas etnográficas; "el campo" próximo-Alicante, Madrid y Palma de Mallorca- fue desde un primer momento el centro de nuestro interés por cuanto se pudieron llevar a cabo acompañamientos en los procesos de llegada, documentación, alojamiento, educación e interacción a los migrantes, lo que nos facilitó el acceso a los y las colaboradoras.

En cuanto a los instrumentos de investigación, es muy habitual que en la investigación con inmigrantes se recurra sino a cuestionarios, preguntas y escalas concebidas originariamente para la población autóctona, sí al menos a ciertos presupuestos conceptuales que le son propios. Sin embargo, las diferencias idiomáticas y culturales de la población inmigrante afectan a la fiabilidad y validez de los instrumentos de medida (Llopis Goig, 2007: 109). El análisis de autobiografías y su importancia en el trabajo etnográfico nos resultaron fundamentales en esta investigación, pese a una de las críticas que se le suele hacer a la herramienta autobiográfica como es la posible caída en las esencializaciones; lo hemos tenido en cuenta, no lo perdemos de vista para evitar desenfoques. 


\section{El lugar de llegada}

El país de destino del/la migrante se encarga de contar el hecho migratorio y por tanto es diseñado por las personas que nunca han querido que llegase, explicándolo desde la problematización; o que, aun deseando la llegada del/la migrante (por ejemplo, desde políticas públicas que fomentan la presencia de trabajadores extranjeros invitados), explican la visita como excepción, como un aprovechamiento del cuerpo migrante.

Pero si hubiese un problema con la llegada de personas a otro territorio, las que llegan deberían ser las voces autorizadas para dibujar el mapa de cada situación vivida, esto es, el proceso "viajero", el de asentamiento o el de sus relaciones endógenas y exógenas con la experiencia. Sería difícil imaginar a Ulises contado por los territorios que lo reciben, pues el héroe homérico es el arquetipo de la salida del hogar y de la lucha por el retomo al mismo, de los peligros que implica el "viaje", de los hogares provisionales que aguardan al viajero (Cragnolini, 2000: 53). La migración entendida en este sentido tendría una parte problemática, un lado oscuro, al que se denomina estrés o duelo migratorio (Achotegui, 2009: 163). El duelo quizás en ningún otro caso se encuentra más prostituido -degradado para obtener un beneficio, el de mantener los privilegios- pues se explota para obtener el poder del discurso, para ello es necesario recordar que siempre estamos en categorías coloniales del lenguaje (Veronelli, 2016). Es preciso por tanto decirle a la administración en el país de llegada que el cuerpo sufre para suscitar su generosidad, lo que Didier Fassin (2005: 203), analizando el campo de la pobreza y de la migración en Francia, denomina "biolegitimidad". En este sentido, el autor expone cómo a finales de los 90 en Francia se puso en práctica por parte del gobierno un Fondo de Urgencia Social ante las necesidades de migrantes, desempleados y precarios. En las solicitudes para entrar al programa existía una valoración objetiva (ingresos, edad, enfermedad, situación laboral...) y una subjetiva a la que los demandantes daban ingreso mediante el envío de una carta donde contaban sus penurias, tristezas, sufrimientos... en lo que el autor vio un "uso político del cuerpo". Se trata, pues, de poseer el discurso de la autovejación para dominar el sistema vejante, el que centra en la responsabilidad individual falencias estructurales. El poder social y el abuso de poder pueden reproducirse por medio de las estructuras del discurso (Van Dijk, 2011: 8; Chakravorty, 2003). Una vez apropiado el discurso se influye en la ideología social que interioriza "el problema de la emigración".

\begin{abstract}
Es -o debería ser- evidente que el núcleo central del llamado "problema de la inmigración" no es el de si podemos o no convivir con la diferencia, sino si podemos convivir o no con el escándalo de la explotación humana masiva indispensable para el actual modelo de desarrollo económico que, en tantos sentidos y al lado de un papel creciente de las más modernas tecnologías, nos retrotrae a las formas más inmisericordes y brutales de abuso sobre la fuerza de trabajo que caracterizaron las primeras fases del taylorismo (Delgado, 2006: 12).
\end{abstract}

La dicotomía la "cultura" propia versus la cultura de los llegados (Delgado, M. 2006: 14) nos devuelve desde la ideología social la imagen de "problema". Porque el forastero aparece para, de algún modo, cuestionarnos (Schutz, 1999). Surgen por tanto diversos interrogantes: ¿Qué es un problema?; ¿la diferencia de lo propio y lo ajeno en cuanto al lugar de nacimiento?; ¿el momento vital en el que llegamos a un territorio?; los neonatos son naturalizados, los menores son aceptados si se asimilan ¿y son, entonces, los mayores de edad un problema? Solo la asimilación es la solución para muchas políticas públicas, así como lo exponen las primeras investigaciones acerca de migración realizadas por la Escuela de Chicago (Terrén, 2001).

Hay una representación muy generalizada del inmigrante, que es expresión de un problema real y central en la vida de los sujetos. Dicha representación resalta su carácter de foráneo, extraño, alguien situado en un determinado margen de la sociedad: bien sea fuera de la misma o dentro, pero en los límites del espacio social (Pazos, y Devillard, 2017: 2).

Por eso, como ya hacía el padre Bartolomé de las Casas, se trata de ignorar todo de ellos, de los "otros" y se justifica entonces su asimilación (léase, dependiendo del momento histórico: evangelización/ conversión/culturización/humanización/civilización/ 
integración) como un medio para mejorar sus condiciones de vida (Todorov, T., \& Burlá, F. B. 1987: 11). O siguiendo a Mary Douglas (1973), el inmigrante/ extranjero podría ser considerado suciedad, materia fuera de lugar, cuerpo en el que habría que realizar algún tipo de ritual para exhorcizar los demonios que per se trae consigo, con el fin de que la sociedad pueda integrarlo (o expulsarlo, dependiendo de la gravedad de sus faltas/ausencias). En otro extremo ignorar todo de la alteridad nos lleva a la contemplación de la misma como un problema y "nuestra cultura" su solución para la humanización, apareciendo los principios y valores de la sociedad de acogida como teleológicos.

La historia de los colonizados comenzaba con la llegada de los colonizadores, con su presencia civilizadora. La cultura de los colonizados no era sino la expresión de su forma bárbara de entender el mundo. Cultura, solo la de los colonizadores [...]. Estos hechos explican cómo, para los colonizados que pasaron por la enajenante experiencia de la educación colonial, la "positividad" de esta educación o de algunos de sus aspectos solo existe a partir del momento en que, al independizarse, la rechazan y la superan, o sea, a partir del momento en que, al asumir con su pueblo, su historia, se injieren en el proceso de "descolonización de las mentes" (Freire, 2000: 23-24).

La posibilidad de crear una humanidad liberadora, como propone Freire, es el inicio mismo de una contracultura, de contar y no dejar que nos cuenten, siendo conscientes de nuestra historicidad. Es pues la interculturalidad, y la crítica a la misma, la que nos marca una nueva línea base para poder pensarnos desde la conciencia de la subalternidad.

Si bien, tal como expone Hobsbawn (1998: 276), "dado que el liberalismo no podía defenderse de manera lógica contra la igualdad y la democracia, erigió la barrera ilógica de la raza: sería la propia ciencia -baza del liberalismo- la que probara que los hombres no son iguales", de lo que se trata es de construir la interculturalidad -así entendida críticamente -, lo que requiere transgredir, interrumpir y desmontar la matriz colonial aun presente y crear otras condiciones del poder, saber, ser, estar y vivir que se distancian del capitalismo y su razón única
(Walsh, 2010: 69). Podemos, debemos, sabemos ser, estar y vivir de diferentes formas, los modos interculturales de hacerlo con la alteridad requieren que alcemos la mirada hacia otras alternativas.

En primer lugar una propuesta de contarnos en simetría y no permitir que "la alternativa única", entendida como el sistema capitalista la entiende, nos inocule esperpentos. La migración, la emicgración contada por los protagonistas no da el centro de la experiencia al que recibe sino al que llega. La urbanidad mínima de la "visita" del emic-grante da espacio al que llega para que responda a las sempiternas preguntas, exclamaciones y arengas: ¿Qué tal?; ¡Cuánto tiempo!; ¿Cómo te va?; ¿Tu familia, bien?; ¿Hasta cuándo te quedarás?

\section{Emic-gración obstáculos para generar un discurso decolonizado}

Pero para que lo antedicho sea efectivo, debemos de despensar ciertas categorías que en las ciencias sociales se han venido trabajando, en un sentido no solo de arrepentirse de lo pensado sino de tratar de llevar a cabo una hermenéutica de los supuestos a priori desde los que analizamos la realidad social. Dichas categorías las exponemos por separado de manera analítica, si bien en la práctica, lo mismo que la interseccionalidad a la que se ve sometida la migrante que llega a un destino ajeno a sus raíces, suelen darse en conjunto y retroalimentarse:

\section{El nacionalismo metodológico. Como obstáculo} en la investigación sociológica respecto de migraciones internacionales ha sido uno de los hándicaps con los que se encuentran hoy las ciencias sociales (Goig, 2000). Esa naturalización del Estado-Nación como ámbito desde el que analizar un fenómeno como el de la inmigración sería, pues, la prueba más evidente de los efectos perniciosos de la «miopía estadocéntrica» en los planteamientos de los investigadores sociales.

El nacionalismo metodológico es el enfoque más común, ya que tanto desde un punto de vista académico como desde una perspectiva popular se piensa que los Estados-Naciones normalmente contienen sociedades (como lo implica, por ejemplo, el concepto de sociedad estadounidense, mexicana, o francesa). Desde esta perspectiva, la aparición de extranjeros que 
siguen vinculados con sus países de origen es vista como algo anormal que interfiere con un todo que, de otra manera, estaría integrado, y como algo que se espera que desaparezca (Waldinger, R. 2013: 190).

Una metodología desde una posición activista requiere del pensar la investigación desde un espacio que llamamos "sin estado", no entendido desde el sentido anarquista tradicional del término sino desde una posición que reclama nuevas cartografías metodológicas y teóricas para entender la migración. El Estado ordena, violenta las entradas, fija márgenes e interviene en ellos. La relación entre la violencia y las funciones ordenadoras del Estado es clave para el problema de los márgenes (Das et al., 2008: 22), y la responsabilidad de la investigación es por tanto la de desenmascarar la responsabilidad del Estado en ordenar sin violencia, ser hospitalario. Por consiguiente, habría que ajustar nuestra ética de la hospitalidad, nuestra política de la hospitalidad, a un más allá del Estado (Derrida, Dufourmantelle, y Segoviano, 2000: 3). La constelación de ciudadanos o mejor dicho no ciudadanos a los que decidimos privar de territorio y por tanto de sentido de pertenencia son criticados por su falta de "integración". En este sentido, Mezzadra (2005) habla de que ha de existir y producirse en diferentes marcos normativos un "derecho de fuga" (Citado en Piñeiro-Aguiar y del Salado, 2017: 12). Es admisible precisar que la noción de comunidad desterritorializada es definida como aquella entidad que ha escapado de la hegemonía totalizadora del Estado-Nación al estar apartada de una localidad específica (Garduño, E, 2003: 10).

La comunidad migrante es, pues, la mayor del mundo en ese circuito hiperespacial que fluye, salta muros, atraviesa océanos, discurre por vías y arenales, sin papeles o con estos mojados como canta Chambao ${ }^{1}$. La atención prestada a las diásporas (Clifford, 1994), a lo híbrido (Canclini, 2012) y a las conexiones globales (Hannerz, 1998) con lo local reflejan, entre otros aspectos, la volatilidad de las fronteras estatales y el descentramiento del marco de análisis estatal para comprender las migraciones.

\section{El racismo del investigador/a. Ser intercultural es} un ejercicio, una práctica vital que necesita remover en el presente, por cuanto dicho presente es también una lucha por todos los pasados que en él se contienen, así como las diversas luchas por la memoria histórica atestiguan. El racismo se ha reinventado a la medida de sus necesidades y ha viajado en el mapa humano sin fronteras. El racismo como cualquier pensamiento rígido, como conjunto de ideas de un momento, necesita una justificación basada en la emoción del sentir epidérmico. La emoción mueve a la acción. Es decir, todo sistema racional tiene un fundamento emocional (Maturana, 1990: 35).

\begin{abstract}
Y por eso la interculturalidad no puede ni prescinde de la emoción, aunque tenga voluntad flexible. Uno, lo emocional es político. Dos, lo emocional es una instancia epistemológica. Es decir, conocemos cuando sentimos. Tres, este conocimiento emocional requiere de una reelaboración productiva, una traducción, para activarse como una acción transformadora (López, H. 2014: 3).
\end{abstract}

Cuando definimos nuestra posición lo podemos hacer desde planteamientos más abiertos o menos, pero lo que se discute aquí es la imposibilidad o no de ser en "la nada". Somos racistas y como investigadores e investigadoras también.

Este racismo es propio de una clase dominante cuya re-producción depende, en parte, de la transmisión del capital cultural, capital heredado que tiene la propiedad de ser un capital incorporado y, por tanto, aparentemente natural, innato. El racismo de la inteligencia es lo que utilizan los dominantes con el fin de producir una "teodicea de su propio privilegio", como dice Weber (Bourdieu, P. 1990: 1).

Entendemos aquí el privilegio como investigadores (Grosfoguel, 2013) desde el momento que no tenemos en cuenta el conocimiento como una instancia epistemológica del que conoce por qué y cómo siente el que migra, el extranjero, el apátrida. Son sentimientos, afirmamos, que si no se tienen en cuenta se incurre en racismo epistémico. El privilegio epistémico y la inferioridad epistémica son dos caras de la misma moneda (Grosfoguel, 2012), donde una cara se considera superior y la otra inferior. Contra esto, una buena estrategia podría ser el caminar hacia un sentipensar (Moraes y de la Torre, 2004; Escobar, 2014). Pero antes de ello hemos de considerar que la raza, la línea de lo 
humano y las jerarquizaciones poblacionales han sido consustanciales a la formación del capitalismo y de las disciplinas científicas. Desde términos como "informante", hoy discutidos, hasta el exotismo de la etnografía, los investigadores vamos dibujando nuestra práctica con una disfrazada cientifidad que pretendiendo objetividad deja al margen el centro, la voz, la historia, la vida, la autorrealidad de las personas que son traducidas por nuestra "experticia".

La definición de racismo es en sí un proceso intercultural. Explicamos el oxímoron porque cada día se reinventa el racismo y cada día hemos de redefinirlo. Ambos procesos entretejidos son un esfuerzo continuo que emerge del trato. Para Margarita del Olmo y Carmen Osuna (2017) desde el rechazo al concepto raza, el racismo es:

Un comportamiento social (y las ideas e instituciones sociopolíticas que lo legitiman) que consiste en clasificar a las personas en grupos sobre la base de diferencias reales o imaginarias, que se asocian a comportamientos cuyo objetivo es justificar una jerarquía entre grupos de personas, haciendo creer que unos son mejores que otros (Del Olmo, y Osuna, 2017: 82).

Las autobiografías de los migrantes no se encuentran escritas y editadas como las "grandes obras" de los "grandes hombres". Estamos más bien ante una antología de vidas. Existencias contadas en pocas líneas o en pocas páginas, desgracias y aventuras infinitas recogidas en un puñado de palabras (Foucault, 1996: 79). El hecho de no contar con el poder de ser enfocados, de que sus vidas no sean iluminadas por los intereses dominantes, de facto. No gozan de las posibilidades de un aparato estatal que busca constituir su legitimidad y tampoco se organizan, como muchas de las "obras nacionales", mediante un modelo argumentativo (Grimson, 1997: 2). Por tanto, pasan a ser letra pequeña, de hombres pequeños, hombres infames en palabras de Foucault (1997). Corremos el riesgo, por tanto, de seguir haciendo una etnografía de medio campo sino tenemos en consideración lo antedicho, por lo que concordamos con Menéndez:

para mí lo preocupante (...) es la escasa producción antropológica sobre racismo en sociedades donde no es asumido como problema no solo por los sectores sociales dominantes, sean neoliberales, neopopulistas o socialistas, sino que casi no es estudiado por los sociólogos, politólogos, psicólogos sociales, y por supuesto por los antropólogos, incluidos los que se dedican a los llamados "estudios culturales" (Menéndez, 2017: 13).

3. Los relatos subalternizados; las autobiografías del/la inmigrante. El resultado es una incipiente pero muy fructífera "interteorización" entre la mirada académica-acompañante y la mirada activista igualmente autorreflexiva (Dietz, 2011: 15). El acompañamiento, para que sea fructífero, requiere del "re-conocimiento" y este no es posible desde el "des-conocimiento". Las orientaciones subjetivas de los actores, aquello a lo que Park se refiere en repetidas ocasiones al hablar lo que "hay tras los rostros" de los individuos (Terrén, 2001: 93). Las autobiografías son por tanto el "relato autorizado" que debemos entender como sustantivo, aún a riesgo de que la etnografía asuma la responsabilidad de completar la oración, conoceremos el centro nominal, sin presunciones de conseguir el centro real, tan lábil, en lo concerniente al acercamiento subjetivo inherente al ser humano. Entendemos, como Pujadas (2000), que la autobiografía es el término favorito utilizado por la mayoría de antropólogos que han combinado etnografía y recopilación de trayectorias personales. Y nos unimos a esta denominación conscientes de otras muchas: biografía, autobiografía, historia de vida, historia personal, narración biográfica, relato biográfico, fuente oral, documentos personales (Pujadas, J. J. 2000: 135). Para ello, no debemos obviar el proceso de subjetivación previo a nuestra relación con nuestros colaboradores en el campo.

La muerte de las vidas relatadas por las y los colaboradores en "el campo" de la etnografía no es un "vitalcidio" 2 en sentido estricto, pues nuestra traducción -la de la transcripción- es una parte de sus vidas, sin embargo, se repite lo que nos gusta entender como racismo del relato. Morir teniendo la culpa es de pobres; los ricos mueren por culpa de "los otros". La visión asimétrica de los investigadores, en ocasiones, nos hace percibir la vida que interpretamos, traducimos, citamos... como la única forma de dar voz, como diciendo (y excusándonos): "no la tendrían sin nosotros, una suerte que queramos escuchar, la investigación como herramienta activista y revolucionaria". Y lo hacemos sin tener en cuenta que son vidas a las que se les roba 
autoría, en parte por la ética del trabajo de campo y en ocasiones porque asumimos la "culpa" de la muerte del relato en que los migrantes, los pobres, los subalternos, no quieren o no saben contarla, suicidan el relato de su vida.

El relato autobiográfico es para nosotros patrimonio cultural, su inmaterialidad, lo hace discutible, pero a nuestro modo de ver ineludible. Este pensar el "patrimonio cultural" en obras materiales e inmateriales abre un espacio al diálogo de saberes (Abeledo, 2017: 32).

La disposición y relación de confianza de los y las colaboradoras fueron los generadores de la primera idea de investigación. ¿Por qué las noticias no hablan de nosotros/as? No dicen quiénes somos ni el nombre de nuestros pueblos, nadie sabe qué lenguas hablamos, dónde estudiamos o si decidimos o decidieron que viniésemos (Mujer, 30 años, origen Ecuador, 2012).

Nuestro estatus de formadores/investigadores/migrantes nos procuró una población de más de trescientos inmigrantes a lo largo del período de 2009-2011. De la población a la que tuvimos acceso (278 migrantes de 9 países), la muestra que compartió con nosotros la experiencia fue de 35 . La selección de la muestra tuvo en cuenta solo la voluntariedad. La diversidad era consustancial, ya que pertenecían a 9 países, rangos de edad entre 18 a 65 años y orígenes socioeconómicos y formativos de amplio espectro. Mujeres y hombres en su mayoría jóvenes -25 tenían entre 20 y 25 años- y de estos 20 hablaban varias lenguas y 14 tenían estudios medios y superiores.

Las 35 entrevistas realizadas fueron acompañadas de cartas que los y las colaboradoras nos facilitaban a modo de autobiografías. Las "cartas largas" como las llamaban, estaban dirigidas a nosotros como receptores de la información, de sus vidas, de la experiencia narrada desde el "yo protagonista". Para facilitar la narración y confianza pactamos que nos vieran como " a un amigo o amiga". Casi todas las cartas empezaban con un saludo inicial al amigo y su familia y eran escritas en lengua materna, wolof, hausa e incluso algunas en lengua colonial -francés, inglés, portugués o el español moldeado con matices según su país de origen- porque era en la que habían estudiado y la sentían más cercana a la hora de escribir. La traducción era hecha por el colaborador para evitar traiciones en el traslado de sus historia a la metodología. Las cartas eran escritas con una cierta regularidad, cada tres meses, en su mayoría. No siempre recogimos los insumos en la fecha pactada y algunos prefirieron contar su carta en videograbaciones.

Las entrevistas fueron realizadas en los procesos de acompañamiento a los migrantes desde su llegada, normalizando las relaciones entre entrevistadores y entrevistados mediante una conversación cuyo punto de arranque fue la obtención de un consentimiento informado. En ocasiones la información no ha podido ser usada. El miedo a ser reconocidos por su relato paralizó contenidos de gran interés. Intentamos suavizar el impacto y la cercanía de las consecuencias comprometiéndonos a publicar pasados al menos algunos años, razón por la que este es el primer artículo con datos sensibles de nuestra experiencia investigadora con autobiografías. Entendemos aun así que los relatos y su interpretación son de la mayor actualidad aun cuando sus principales protagonistas estén ya en otras situaciones vitales.

\section{Sexo-piel-papel en los relatos y en los cuerpos}

Llegados a este punto. $\mathrm{Y}$ asumiendo que la simetría en la investigación es importante para que las subjetividades sean vistas como riquezas, también ponemos en valor que como investigadores/ migrantes y herederos de migrantes la empatía es una herramienta fundamental, para asumir nuestras propias carencias a la hora de comprender la complejidad sistémica cuando confluyen opresiones, que son agravantes y multiplicadoras. De que "la relación" entre "raza", sexualidad y migraciones adquiere características particulares y configura una relación universal desde la que se construyen paradigmas seudocientíficos que tienden a consolidar una mirada común sobre los inmigrantes, especialmente sobre los "negros" (Tijoux, 2014: 2).

Una tríada, un bloque monolítico, que acompaña a la extranjera, a la que trae de fuera, su piel, sin papeles y como mujer. Estos mecanismos de exclusión se mueven en un doble plano, material o simbólico, de modo que envuelven tanto las prácticas dominantes como las actitudes que las legitiman (Rubio, S. P. 2003: 17). Podemos definir dicha exclusión como "el apartamiento o alejamiento del núcleo central de una sociedad o grupo, no de carácter voluntario, sino forzado y en conexión generalmente con variables de raíz étnica" (Solé, Alarcón, y Gibert, 2000: 133). 
¿Por qué las mujeres africanas migran menos? ¿Por qué las mujeres sudmeriacnas migran más? Aunque en los últimos estudios los números se equiparan, no deja de haber una historia de mayor emigración joven-masculina africana, y joven-femenina sudamericana. Preguntamos a los colaboradores que nos apoyaron durante la investigación para saber si nos podían dar luz sobre la duda:

\section{Porque resisten mejor las necesidades y si tienen hijos ya no pueden y siempre tienen hijos. Saben controlar la natalidad, toman semillas pero ser mujer para ellas y para nosotros es tener hijos, alcanzan mejor posición social (hombre, 27 años, origen Sudán, 2009).}

Nuestro racismo como investigadores nos había hecho partir de la idea de que quizás el periplo era más duro para una migrante por ser mujer, o que quizás los ahorros de la familia que se invierten en muchas migraciones se consideraban una mejor inversión con los hombres, pero las respuestas fueron en la dirección de asegurar que la resiliencia en el caso de la mujer era mayor y por ello tenían menos "interés" en migrar. O que eran más deseadas por sus habilidades como cuidadoras y cocineras.

\section{Porque nuestras mujeres tienen sazón en la cocina y respetan a los adultos mayores. En Europa abandonáis a los adultos mayores (hombre, 30 años, Ecuador).}

A partir de esta pregunta rediseñamos muchas otras pues nos dimos cuenta de que nuestro racismo había permeado la investigación, y no solo por medio de los instrumentos. La ideología social se había instalado sin haberla percibido. Esto abrió nuevos interrogantes: ¿Por qué la piel es frontera?

En "La última cena"” de Gutiérrez Alea el cimarrón sería la condensación metafórica de una diferencia irreductible (Hernández, 2003: 840). Quizás el miedo a la irreductibilidad, o también. En dicha obra, la metaforización del blanqueamiento y del mestizaje se produce en el relato de la elaboración del azúcar refinada a partir de la melaza negra, hecho por Don Gaspar, el químico mulato que ha escapado del Haití controlado por los negros sublevados y quien se encuentra a la cabeza de la modernización del proceso productivo del ingenio. En el miedo a perder la "supuesta patente del ingenio", quizás el mestizaje que surje es menos aprehensible que las dicotomías blanco-negro. El blanqueamiento entendido como contaminante de la esencia surge como una amenaza en los territorios de salida. La transculturación no es siempre vista como una posibilidad, al contrario, se puede considerar un híbrido aberrante.

La piel al igual que en el ingenio del azúcar sale negra y se vuelve blanca, no en su color, evidentemente la metáfora la utilizamos para explicar cómo sobre la piel se tatuan acusaciones. Los y las migrantes que suavizan su acento, que cambian su estatus económico, que estudian, que se enamoran o casan con "los/as otros/as". Cuando retornan son acusados de blanqueamiento, la mirada sobre la piel es un lugar común en África y Sudamérica donde nos cuentan que quizás quieren "mejorar la raza".

\section{No puedo hacer lo que me propones porque cuando llegue a mi aldea me van a acusar de "blanco" (hombre, 28 años, origen Senegal, 2011).}

Nos decía uno de nuestros colaboradores cuando le proponíamos que prosiguiese sus estudios en el país de llegada. De algún modo negarse a la transculturación, conservar su estatus de "calibán", es el modo de ser emic-grado, de poder retornar y contarse a los que lo reciben "auténticamente". Lo contrario no le permite mantener y que le mantengan "respeto".

Pero las discriminaciones raciales en el África de hoy en día son, como lo eran en Santo Domingo, cuestiones de política gubernamental, aplicada con balas y bayonetas, $\mathrm{y}$ hemos vivido lo suficiente para ver cómo los gobernantes de una nación europea convertían a su abuela aria en algo tan precioso para los habitantes del país como lo era el antepasado caribe para el mulato (James, y García, 2003: 55).

Las diferencias tienen un interés último y es colocarnos en una posición de poder. Esta forma de poder se ejerce en la vida cotidiana inmediata que clasifica a los individuos en categorías, los designa por su propia individualidad, los ata a su propia identidad, les impone una ley de verdad que deben reconocer y que los otros deben reconocer en ellos. Es una forma de poder que transforma 
a los individuos en sujetos. Hay dos significados de la palabra sujeto: sometido a otro mediante el control y la dependencia. y sujeto atado a su propia identidad por la conciencia o el conocimiento de sí mismo. Ambos significados sugieren una forma de poder que subyuga y somete.

El sometimiento es entonces la identidad de emic-grado, la forma de contarse a sí mismo que dimana de la forma que lo cuenta la sociedad que lo recibe, no lo acoge, lo clasifica para poder subyugarlo. Son sujetos, atados a los relatos, a la falta de autonomía, a la dependencia de la tecnocracia que los desindividualiza bajo epígrafes como "subsaharianos", "latinos", "extracomunitarios". La individualización permite la humanización y esta no se da porque el poder se diluiría. La categorización impide la individualidad y es un mecanismo de control utilizado desde instancias de poder. Así, como expone Todorov (1991), todo sistema clasificatorio dice más del clasificador que del clasificado.

\section{A nadie le importa cómo se llama mi pueblo, todos me preguntan por mi país y yo mi país no lo conozco, no sé cómo explicar que un pueblo es "mi país" (mujer, 25 años, origen Camerún, 2012).}

Partíamos de otro sesgo y era el de que migrar siendo negro/negra dificultaba el proceso de asentamiento cuando el país de recepción era mayoritariamente blanco. Aunque defendamos un enfoque intercultural desde una perspectiva de la interacción. El interés central del enfoque de Park radica en reducir la raza a un elemento simbólico de la interacción (Terrén, 2001: 95). El marco legal vuelve una y otra vez una realidad racializada a priori en la que el profiling o perfilaje étnico mara la relación jerárquica Estado-sujeto (Brandariz, 2008).

Nuestro problema no es la llegada, son las leyes, en Ecuador por ejemplo solo piden visado a países negros (hombre, 20 años, origen Ecuador, 2010).

Observemos que los propios colaboradores comparan las leyes de sus países de origen -como en este último caso Ecuador- con las vicisitudes que deben pasar en destino. La pregunta hacia el asentamiento también estaba contaminada, no es la convivencia el mayor obstáculo, son los legisladores, en muchos casos. Leyes como la Ley Orgánica 4/2000, de 11 de enero, sobre derechos y libertades de los extranjeros en España y su integración social dicen por una parte (Artículo 7. Libertades de reunión y manifestación. 1) que los extranjeros tienen el derecho de reunión en las mismas condiciones que los españoles. Sin embargo nos comentan nuestros colaboradores que la policía los disgrega so pena de detención:

\section{Para casa nos dicen, no podéis estar todos juntos en la calle que no habláis de nada bueno (hombre, 25 años, origen Sahara, 2010).}

Cuando acudimos a los y las colaboradoras su relato desmitifica las dificultades de relación cotidiana. Cifran sus obstáculos en moneda.

Es cierto que algunos "ignorantes" de vuestro país nos preguntan cosas muy absurdas y que resultan incómodas como si hay televisión en mi país. Yo le respondí que en las tiendas muchas y en las casas más de las que debiera haber porque cuentan muchas mentiras, pero estoy seguro de que a los jugadores de fútbol negros no les preguntan esas cosas. Me ven pobre y aunque ellos lo son asocian negro a aldea (hombre, 26 años, origen Ghana, 2011).

\section{Yo trabajaba como escribiente de un notario $y$ dejé de ponerlo en mi curriculum porque un día me dijeron "Así serán los notarios allá, porque aquí... ni hablas bien”. Hablo cuatro idiomas pero con acento y eso no agrada. En el fondo el acento cuesta dinero y si no tienes el adecuado, cobras menos, ¿no? (mujer, 45 años, origen Sahara, 2010).}

¿Papel estucado? Muchos de los colaboradores hablan de "hacer desaparecer" sus papeles de origen para evitar deportaciones. Cuentan de papeles de países de paso que facilitan unos a otros porque los negros somos todos iguales para los blancos (hombre, 25 años, Senegal, 2011) -aprovechar el racismo en su favor, esto ocurre en Mali-, lo que les da alguna ventaja, la terrible desindividualización. O de utilizar la posibilidad del doble pasaporte y olvidarse del de el país sudamericano. De este modo las sociedades que presumen controlar sus fronteras con papeles se 
desfiguran. El crecimiento de las desigualdades es a la vez el indicio y el motor de este desgarramiento. Es la lima sorda que produce una descomposición silenciosa del lazo social y, en forma simultánea, también de la solidaridad (Rosanvallon, 2012: 17). La exigencia de papeles estucados: brillantes, sin manchas, encerados, ornamentados, tallados y los múltiples lustres que se pueden generar no es más que la manifestación de la descomposición de una sociedad que cree poder leer mediante "papeles estucados" a individualidades que no contempla. Entierros, indeseados, como sus llegadas -las autoridades han de buscar a sus familiares, no lo hacen o no siempre y sus familias, en ocasiones, prefieren duelo sin cuerpo que cuerpo con gastos- salidas, vidas y muertes.

¿Vulneración principal de la autobiografía?

\section{Cuando quemaron mi aldea, pude escuchar} a lo lejos la voz de mi hermano, por eso ahora lo busco. No sé en qué país está, pero creo que como es listo, se habrá ido a uno que no te puedo decir... no se trata de tener confianza, confío, pero tú no sabes que mucha gente aparenta lo que no es y si me delatan no tengo ninguna posibilidad... aunque esté muy lejos, no importa, tú no has visto freir a un niño como un buñuelo, delante de su madre... no me digas que estoy seguro, tú no sabes nada... papeles, no me importan, estoy tranquilo, si nadie sabe de mí... estoy tranquilo (hombre, 28 años, origen Sudán, 2010).

\begin{abstract}
Mi trabajo es de cuidadora, todos en mi familia reciben el dinero por Western Union y mis hijos están en una escuela fiscomisional. Nadie pregunta cómo se gana tanto cuidando a un adulto mayor y yo le digo que el Municipio da ayudas... si vuelvo tendré que vivir y... diosito me perdone no puedo contar (mujer, 25 años, origen Ecuador).
\end{abstract}

Esto va más allá del deseo de una "desatención cortés" (Goffman, 1971) por parte del autóctono hacia el forastero, pues lo que el migrante busca es el más extremo anonimato, cierta invisibilidad ante las instancias de poder. Difícil paradoja la de verse entre la búsqueda de integración (papeles, trabajo, vivienda) y el deseo de pasar inadvertido, debido al temor que sucinta cualquier encuentro indeseado con la autoridad.

\section{Conclusiones}

Las inconclusiones del ser "humano" son las conclusiones de lo inacabado de nuestra humanidad. Al igual que el nivel moral recíproco, base de la cultura, como es el intercambio: te doy si me das (Mauss, 2009). La elevación de la humanidad a niveles morales interculturales está todavía "en obras" por cuanto dicho intercambio o no se da o es asimétrico. Las diferencias en este sentido siguen siendo medidas de valor. Vales más si tus diferencias son cotizadas por la idea hegemónica de "hombre blanco occidental no migrante". En este sentido el racismo

puede ajustarse a las variantes pragmáticas que necesitan aplicar las sociedades capitalistas para asegurar su continuidad. Posiblemente sea la ideología que más ha contribuido a establecer los criterios de inferioridad y superioridad con que se categoriza a los diferentes sujetos sociales, constituyendo uno de los más persistentes mecanismos de hegemonía/subalternidad, no solo en términos de relaciones coloniales, sino también de clase social (Menéndez, 2017: 31).

Migrar no es lo mismo que viajar, migrar no es lo mismo que hacer una estancia, migrar no es lo mismo que estar invitado, migrar no es lo mismo que trasladarse, migrar no es lo mismo que explorar... no es lo mismo, es diferente y solo es diferente.

El Estado-Nación es la excusa sine qua non para poder llamar migrante, diferente, a otro ser humano. Por lo que la decisión de investigar. Evitando el "nacionalismo metodológico" que nos lleva a pensar el fenómeno dentro de los límites de las fronteras nacionales (González Miranda, S. 2014: 44). Y que a la medida de "mi país" entendemos que construye imaginarios que hacen depender el "poder" del país receptor de su capacidad de impermeabilización al "bárbaro", al otro, a la alteridad. Si diluimos el Estado-Nación, si permeabilizamos sus fronteras, si convenimos la invención de la tradición, estamos más cerca de nosotros mismos. Por tanto, parte de la interculturalidad depende de la ruptura de fronteras físicas y mentales, de ser capaces de abolir 
el posesivo que antecede a país, ser capaces de decirnos sin territorio acotado. ¿Somos sin EstadoNación? Sí somos, pero falta concluir si queremos ser. Ser sin violencia, convivir sin diglosia o por el contrario reificar a los humanos en números de entrada y salida.

Los autorretratos, las autobiografías, carecen de poder social si no son transversalizadas y traducidas por el "conocimiento hegemónico"; y esta interpretación de las vidas, por los que detentan el discurso, son alegatos a la disolución del "ser diferente". La interculturalidad crítica y el nacionalismo metodológico nos han servido para discutir acerca de lo que suponemos obstáculos de una investigación decolonizada.

La crítica al trabajo de campo que no tiene en cuenta la voz sin direccionar, la voz subjetiva e intersubjetiva respecto del hecho de la migración nos ha llevado a la autobiografía, y sin ella, no creemos que sea posible la investigación concerniente a la migración.

Cuando el hecho diferencial se asume por un documento, un pasaporte pobre, este se convierte en un argumento para el racismo. Los pasaportes ricos discriminan, pero no ejercen racismo, porque no toda discriminación es racismo; pero si todo racismo hace responsable, culpabiliza a la víctima.

El territorio entendido, en esta ocasión como Estado-Nación, parece que da un lugar en el mundo que se encuentra clasificado antes de nuestro nacimiento. Somos responsables de haber nacido en un país categorizado como: tercer mundo, pobre, en guerra... Tenemos la culpa. Otra vez el que goza de privilegios señala "con letra escarlata".

La "interculturalidad crítica" no permite más que una acción proactiva en un tiempo presente, con el ánimo de cambiar el futuro; sin embargo, el pasado es la carga estereotipada del "que llega" y no ha estado antes en un lugar en el mapa llamado país. La emic-gración trata del hecho migratorio contado desde la experiencia personal y en el lugar de llegada -lo que supone un diálogo endógeno y exógeno- sin cédula, visa, ni credenciales de regularización. La diferencia entre extranjero y emigrado/a es básicamente que el segundo/a se instala para conseguir una vida diferente, supuestamente mejor.

El hecho fronterizo que aísla a los países constituye un repelente a la alteridad, siendo la lucha por la aceptación de piel y la obtención de papeles la guerra silente más prolongada y cruel de la historia de la humanidad. Muchos son los casos con los que a lo largo de intervenciones educativas hemos convivido y desde ese punto de vista la emic-gración de mujeres desde África y Sudamérica a España y su modo de contarlo y vivirlo ha sido nuestro estudio de caso durante un largo período, como parte de un proyecto de fondos FEI. El "trato" contraintercultural dado al y la que cruzan una frontera muta cuando el "género" interviene como construcción fronteriza -la frontera del género es una excusa para el maltrato- entre el sentir y el ser. Como mujer el relato emic-grante se encuentra en el fango racista de más amplio espectro.

Hemos aprendido que en las Ciencias Sociales las metodologías empleadas y sus instrumentos no se pueden desprender de la subjetividad de los investigadores, pero si "la voz" es el centro, y la "escucha activa empática" se posicionan como transversales, es posible comprender complejos sistemas de poder, que pretenden poseer los privilegios, y que se perpetúan cuando no somos capaces de discutir y repensar las metodologías. Concluimos que sacar de la complicidad racista a la investigación, requiere de nuevas ingenierías pensadas con los y las colaboradoras.

\section{Referencias Citadas}

Abeledo, G. G.

2017 Balbinos y Manolitos: Investigación sobre "diglosia convivencial" villa-aldea (del prestigio y privilegio de unos sobre otros). Revista Latina de Sociología, 7 (2).

Achotegui, J.

2009 "Migración y salud mental. El síndrome del inmigrante con estrés crónico y múltiple (Síndrome de Ulises)". Zerbitzuan, 46, 163-171.

Appadurai, A.

2008 "Los riesgos del diálogo". Quaderns de la Mediterrània. Cuadernos del Mediterráneo (10), 268-270.
Brandariz, J. A.

2008 "La construcción de los migrantes como categoría de riesgo: fundamento, funcionalidad y consecuencias para el sistema penal". En Cancio, M.; Pozuelo, L. (coords., 2008) Política criminal en vanguardia: Inmigración clandestina, terrorismo, criminalidad organizada. Navarra: Cizur Menor: 143-196.

Bourdieu, P.

1990 El racismo de la inteligencia. Sociología y Cultura, Editorial. Grijalbo.

Canclini, N. G.

2012 Culturas híbridas. Debolsillo. 
Clifford, J.

1994 "Diasporas". Cultural Anthropology, 9 (3), 302-338.

Clifford, J.

1998 Dilemas de la cultura. Antropología, literatura y arte en la perspectiva posmoderna. Barcelona: Gedisa.

Chakravorty Spivak, G.

2003 “¿Puede hablar el subalterno?”. Revista Colombiana de Antropología, 39, 297-364.

Cragnolini, M. B.

2000 "La metáfora del caminante en Nietzsche de Ulises al lector nómada de las múltiples máscaras”. Ideas y Valores, 49 (114).

Crenshaw, Kimberlé W.

1991 "Mapping the Margins: Intersectionality, Identity Politics, and Violence against Women of Color", Stanford Law Review, Vol. 43, N 6, pp. 1241-1299.

Collins, P.H.

2000 "Gender, Black Feminism, and Black Political Economy". Annals of the American Academy of Political and Social Science, 568. 41-53.

D. G. Y. F. V.

2010 "La interseccionalidad como desafío al mainstreaming de género en las políticas públicas". Revista Vasca de Administración Pública (87-88), 225-252.

Darko, A.

2003 Más allá del horizonte. El Cobre.

Das, Veena, Poole, Deborah, Daels, María, \& Piñeiro, Julia. 2008 "El estado y sus márgenes: Etnografías comparadas". Cuadernos de Antropología Social (27), 19-52.

Delgado, $\mathrm{M}$.

2006 "Nuevas retóricas para la exclusión social. Flujos migratorios y su (des) control". Puntos de vista pluridisciplinarios, 1-24.

Del Olmo, M., \& Osuna, C.

2017 "Racismo. Un análisis desde el poder y los privilegios". Educación Intercultural (3), pp. 77-107) Madrid: UNED.

Derrida, J., Dufourmantelle, A., \& Segoviano, M.

2000 La hospitalidad. Buenos Aires: Ediciones de la Flor.

Díaz de Rada, Á.

2012 Cultura, antropología y otras tonterías. Madrid: Trotta.

Dietz, G.

2011 "Hacia una etnografía doblemente reflexiva: una propuesta desde la antropología de la interculturalidad". AIBR, Revista de Antropología Iberoamericana, 6 (1), 3-26.

Douglas, M., \& Simons, E.

1973 Pureza y peligro: un análisis de los conceptos de contaminación y tabú. Madrid: Siglo Veintiuno de España.

Escobar, A.

2014 Sentipensar con la tierra: nuevas lecturas sobre desarrollo, territorio y diferencia. Ediciones Unaula.

Fassin, D.

2005 "Gobernar por los cuerpos, políticas de reconocimiento hacia los pobres y los inmigrantes". Educação, XXVIII (2), 201-226.

Foucault, M.

1996 La vida de los hombres infames. La Plata, Argentina: Editorial Altamira.

Freire, $\mathrm{P}$

2000 Cartas a Guinea Bissau. Apuntes de una experiencia pedagógica en proceso. Madrid: Siglo XXI.

García Linera, Á.

2008 La potencia plebeya. Acción colectiva e identidad indígena, obrera y popular en Bolivia, Buenos Aires, CLACSO/Prometeo.
Garduño, Everardo

2003 Antropología de la frontera, la migración y los procesos transnacionales. Frontera Norte.

Goffman, E.

1971 La presentación de la persona en la vida cotidiana. Buenos Aires: Amorrortu.

Goig, R. L.

2007 "El 'nacionalismo metodológico' como obstáculo en la investigación sociológica sobre migraciones internacionales". Empiria. Revista de Metodología de Ciencias Sociales (13), 101-120.

Grimson, A.

1997 "Relatos de la diferencia y la igualdad. Los bolivianos en Buenos Aires". Nueva Sociedad, 147, 96-107.

González Miranda, S.

2014 "Las inflexiones de inicio y término del ciclo de expansión del salitre (1872-1919): Una crítica al nacionalismo metodológico". Diálogo Andino (45), 39-49.

Grosfoguel, R.

2013 Racismo/sexismo epistémico, universidades occidentalizadas y los cuatro genocidios/epistemicidios del largo siglo XVI. Tabula Rasa (19).

Hannerz, U.

1998 Conexiones transnacionales. Gente, cultura, locales. Madrid: Cátedra.

Hernández, J. A.

2003 "Multitud, devenires y éxodo: La última cena de Tomás Gutiérrez Alea". Revista Iberoamericana, 69 (205), 839-848.

Hobsbawn, Eric

1998 La era del capital, 1848-1875, Barcelona, Grijalbo/ Mondadori.

James, C. L. R., \& García, G. R.

2003 Los jacobinos negros: Toussaint L'Ouverture y la Revolución de Haití. Madrid. Tumer Publicaciones, S.L.

Mauss, $\mathrm{M}$.

2009 Ensayo sobre el don: forma y función del intercambio en las sociedades arcaicas. Buenos Aires: Katz Editores.

Menéndez, E. L.

2017 Los racismos son eternos, pero los racistas no. México D. F: UNAM.

Maturana, H. R.

1990 Emociones y lenguaje en educación y política. JC Sáez Editor.

Moraes, M. C., \& de la Torre, S.

2004 Sentipensar: fundamentos e estratégias para reencantar a educação. Vozes.

Pazos, A., \& Devillard, M. J.

2017 "La construcción cotidiana de la legitimidad del sujeto inmigrante en el contexto español actual". Alteridades (53).

Piñeiro, E., \& del Salado, M.

2017 "Las Fronteras de los migrantes. Un ejemplo de Ecuador". Revista Qualitas No 13, junio 2017, pp. 6-25.

Pujadas, J. J.

2000 "El método biográfico y los géneros de la memoria". Revista de Antropología Social (9).

López, H.

2014 "Emociones, afectividad y feminismo". García, Adriana y Olga Sabido, coords., Cuerpo y afectividad en la sociedad 
contemporánea, México, D. F.: Universidad Autónoma Metropolitana, 257-275.

Llopis Goig, R.

2007 “El 'nacionalismo metodológico' como obstáculo en la investigación sociológica sobre migraciones internacionales". EMPIRIA. Revista de Metodología de las Ciencias Sociales, (13).

Solé, C., Parella, S., Alarcón, A., Bergalli, V. \& Gibert, F. 2000 "El impacto de la inmigración en la sociedad receptora", en Revista Española de Investigaciones Sociológicas, $\mathrm{N}^{\circ} 90$ (2000): 131-157.

Suárez-Navaz, L., Maciá Pareja, R., \& Moreno García, Á. 2007 Las luchas de los sin papeles y la extensión de la ciudadanía. Perspectivas críticas desde Europa y Estados Unidos. Madrid: Traficantes de sueños.

Pike, K. L.

1967 Language in relation to a unified theory of structure of human behavior, 2nd ed. The Hague: Mouton.

Platero, R.

2012 Intersecciones: cuerpos y sexualidades en la encrucijada. Bellaterra. Barcelona.

Rosanvallon, P.

2012 La sociedad de iguales. Buenos Aires. Ediciones Manantial.

Rubio, S. P.

2003 "Mujer, inmigrante y trabajadora: la triple discriminación" (Vol. 36). Anthropos Editorial.

Speed, S.

2006 "Entre la antropología y los derechos humanos. Hacia una investigación activista y comprometida críticamente". Alteridades, 16 (31): 73-85.
Schutz, A.

1999 El forastero. Ensayo de psicología social. Amorrortu Editores.

Terrén, E.

2001 La asimilación cultural como destino: el análisis de las relaciones étnicas de R. Park.

Tijoux, M. E.

2014 “El Otro inmigrante 'negro' y el Nosotros chileno. Un lazo cotidiano pleno de significaciones". Boletín Onteaiken, 17, 1-15.

Todorov, $\mathrm{T}$.

1991 Nosotros y los otros: reflexión sobre la diversidad humana. México D.F.: Siglo XXI.

Todorov, T., \& Burlá, F. B.

1987 La conquista de América: el problema del otro. México. DF: Siglo XXI .

Van Dijk, T. A.

2000 El discurso como interacción social (Vol. 2). Barcelona: Gedisa.

Van Dijk, T. A.

2011 Discurso y poder. Editorial Gedisa.

Veronelli, G. A.

2016 "Sobre la colonialidad del lenguaje". Universitas Humanística 81. Julio-diciembre 2016: 33-58.

Waldinger, R.

2013 Más allá del transnacionalismo: Una perspectiva alternativa de la conexión de los inmigrantes con su país de origen.

Walsh, C.

2010 "Interculturalidad crítica y educación intercultural". Construyendo Interculturalidad Crítica, 75-96.

Notas

1 Banda de música española, encabezada por la artista del mismo nombre, que fusiona flamenco con música electrónica. La canción a la que nos referimos es "Papeles mojados", de su disco "Con otro aire" (Sony Music, 2007), la que está centrada en el tema de la migración en el Mediterráneo, zona en la que según la artista "muxos [sic] no llegan/se hunden sus sueños/papeles mojaos [sic]/papeles sin dueño.

2 Llamamos "vitalcidio" a la muerte por ostracismo social de la parte de la vida de una persona migrante. No es una muerte total pues la etnografía utiliza herramientas que ayudan a "la voz" de la y el colaborador pero también somos conscientes de que como investigadores seleccionamos las partes que creemos relevantes. No podemos asegurar que sean las que los y las migrantes seleccionarían. Es una muerte de la voz pobre, migrante.

3 "La última cena" del director Tomás Gutiérrez Alea es una película que sitúa en el siglo XVIII una acción dramática acerca de una plantación esclavista y que de un modo metafórico nos ayuda a reflexionar respecto de implicaciones de la esclavitud ligada a la negredad. 
